\title{
Холестеатом на външния слухов проход
}

\author{
Д. Пазарджиклиев ${ }^{1}$, Р. Семова², Г. Хаджигеоргиев² \\ ${ }^{1}$ Медицински университет - Пловдив, Катедра по УНГ-болести \\ 2Медицински университет - Пловдив, \\ Катедра по образна диагностика, нуклеарна медицина и льчелечение
}

Резюме:

Холестеатомът на външния слухов проход и кератозис обтуранс са две състояния с потенциал за сериозни усложнения, чието разграничаване в някои случаи може да бъде трудно. Етиопатогенезата на холестеатома е неясна и едва наскоро тя е частично уточнена. Той може да бъде и от травматичен произход, какъвто могат да имат и дефектите на тегмена на темпоралната кост. Въпреки това такова съвпадение в литературата не е описано. Ние представяме случай на пациентка с холестеатом на външния слухов проход и контралатерален дефект на тегмена и обсъждаме възможната етиопатогенеза в този случай.

\section{Въведение}

Холестеатомът на външния слухов проход (ВСП) и keratozis obturans са две състояния на външното ухо, разграничени за първи път от Пипергердес през 1980 $\Gamma^{1}{ }^{1}$ Клинико-патологичните характеристики, описани от него, обаче се срещат в описанията и на двете състояния. В последните години като основна разлика между двете се приема типьт на костната деструкция, като при холестеатома е налице секвестрация и остеонекроза.

От многото съобщения в литературата е видно, че и двете състояния могат да обхванат и средното ухо и да доведат до усложнения, което налага хирургично лечение. Според нас това още повече затруднява диференцирането на двете състояния.

Дефекти на тегмена на темпоралната кост се наблюдават в до $34 \%$ от анатомичните проучвания. ${ }^{2}$ Те могат да са резултат и от травма, която е етиологичен фактор и за холестеатомите на ВСП. ${ }^{3,4}$ Въпреки това същевременното наблюдение на холестеатом на ВСП и дефект на тегмена контралатерално не е описано.

\section{Клиничен случай}

Тридесет и осем годишна жена беше насочена към УНГ клиника на Медицински университет - Пловдив, с диагноза холестеатом, поставена преди 7 години, като единственото оплакване на пациентката било намаление на слуха, никога не се е оплаквала от гноетечение или болки. Била лекувана с периодичен 
тоалет на холестеатомните люспи до момента, в който при направена компютърна томография (КТ) била установена деструкция на задната стена на канала към праговите клетки и деструкция на предната - към темпоромандибуларната става. (фиг. 1) Отоскопично се откриха холестеатомни люспи, покриващи стените на костната част на ВСП и тъпанчевата мембрана, която бе интактна, но самият канал бе разширен, латералната стена на хипотимпанума бе резорбирана, а фиброзният анулус все едно висеше разположен между кожа и лигавица, лишен от сулкус. ВСП бе очевидно разширен в горно-задна посока. На КТ се забелязваше деструкция на задната стена, латералната стена на cavum tympani и стената на темпоромандибуларната става, което бе потвърдено и интраоперативно. Тоналната прагова аудиометрия показа проводно намаление на слуха от 39 дБ.

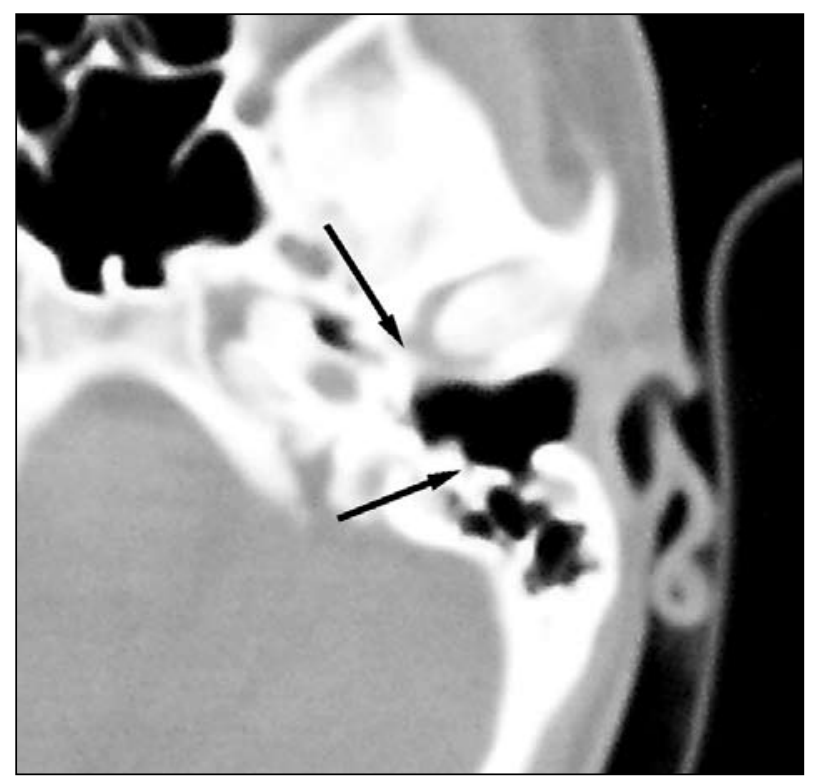

Фиг. 1

При анализирането на томографското изследване се установи деструкция на тегмена на противоположното ухо, което обаче клинически бе напълно здраво. (фиг. 2) Извършеният ядреномагнитен резонанс показа наличието на малко менингоенцефалоцеле. (фиг. 3)

Необичайната находка от холестеатомоподобен материал в костната част на външния слухов проход от дясно и наличието на менингоецефалоцеле от другата страна ни накара да свалим насочена анамнеза, при която се установи, че пациентката е претърпяла пътна злополука с автомобил 10г. преди откриването на холестеатома. При този инцидент тя е имала тежка гръдна травма, поради което е хоспитализирана в хирургично отделение на районна болница. Освен това е имала и рана на главата и данни за контузия на мозъка със загуба на съзнание за няколко часа и амнезия. За съжаление скенер не е бил направен и не е била потвърдена или изключена фрактура на черепната основа. Независимо от това пациентката си спомня за наличието на кръв от дясното ухо и намален слух, който постепенно се възстановил.

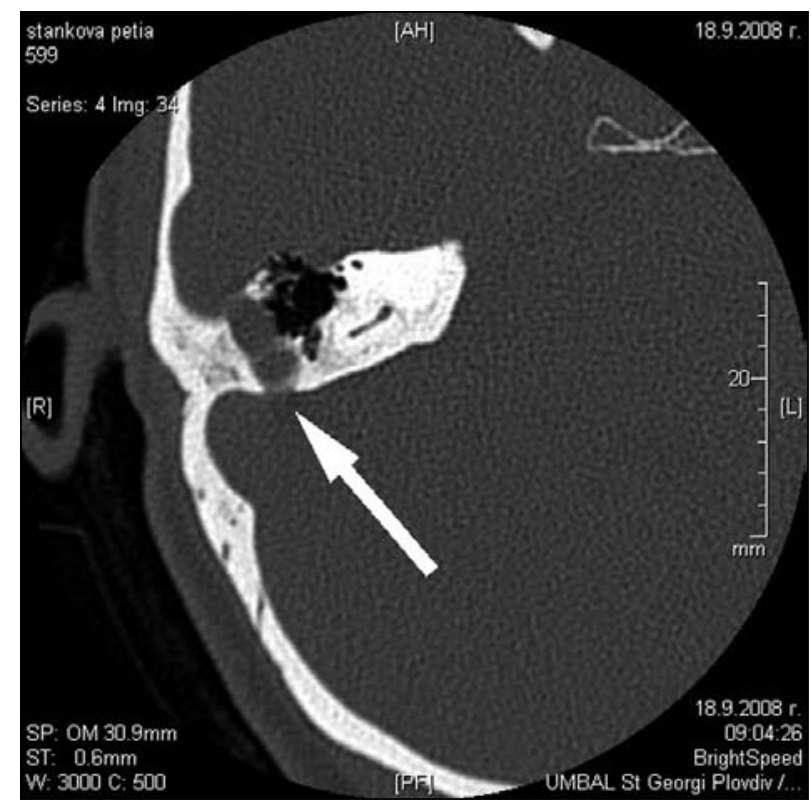

Фиг. 2

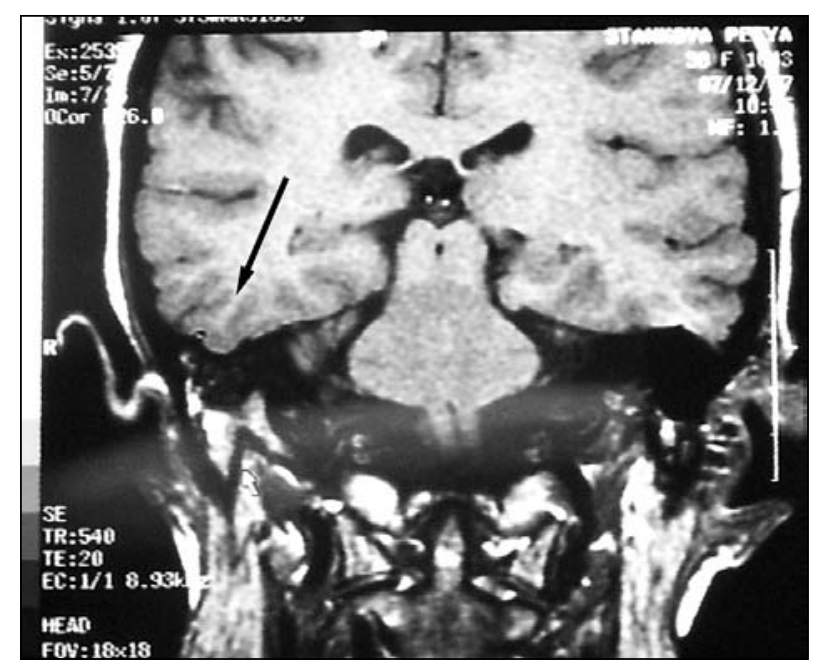

Фиг. 3

Въз основа на тази информация ние приехме диагнозата посттравматичен холестеатом на външния слухов проход с контралатерален дефект (фрактура) с последващо менингоенцефалоцеле от травматичен произход. Извършена бе консервативна радикална трепанация на лявото ухо, а по отношение на дясното пациентката е под наблюдение и инструктирана за възможните усложнения. (фиг. 4) 


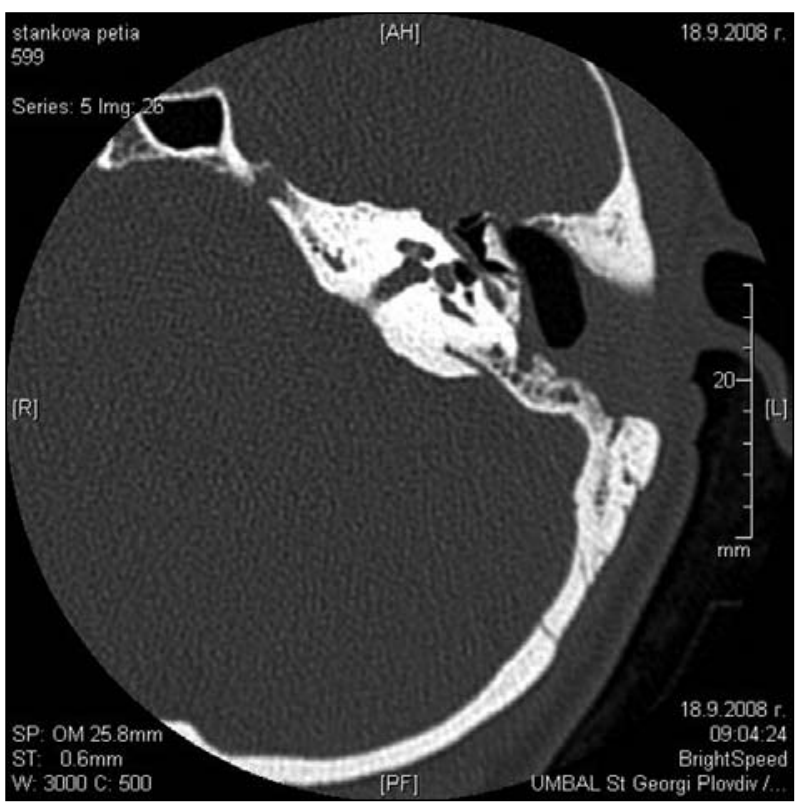

Фиг. 4

Понастоящем пациентката е без оплаквания, но въпреки това тьпанчевата мембрана продължава да е покрита с кератинови люспи.

\section{Дискусия}

Холестеатомът на външния слухов проход и кератозис обтуранс са две състояния на външния слухов проход, при които е налице задръжка на кератинов материал. ${ }^{5}$ Двете бяха разграничени от Пирпергердес на базата на клиничните им характеристики. Въпреки това много съобщения и проучвания показват, че симптомите им се припокриват и диференциацията им може да се окаже трудна задача. Поради това в литературата е налице стремеж да се установи тази тяхна характеристика, която да ги разграничи дефинитивно. ${ }^{6}$ Типично за холестеатомите бе определено наличието на остеонекроза и костни секвестри без кожна покривка. ${ }^{7}$ ${ }^{8}$ Наскоро Наим класифицира холестеатомите според тежестта на тези изменения. ${ }^{9}$ Добре известно е обаче, че и двете състояния могат да прогресират до там, че да ангажират съседни структури като темпоромандибуларната става, кавум тимпани, клетъчната система на мастоида и лицевия нерв. ${ }^{10}$ 11, 12, 13 На този етап тези две „различни“ сьстояния, с неизвестна етиология и патогенеза, налагат едно и също лечение - хирургично..$^{9-13}$

В нашия случай, въпреки че са налице някои характерни за кератозис обтуранс белези, ние приехме диагнозата холестеатом поради следните факти: 1) състоянието бе с изразен потенциал за усложнения, характерни за холестеатома (поради ангажирането на съседни структури); 2) налице бе анамнеза за травма, която е добре известен етиологичен фактор за холестеатомите на външния слухов проход $\left.{ }^{4}, 14,15 ; 3\right)$ наличие на контралатерален дефект на темпоралната кост, също с възможна травматична генеза. Въпреки сравнително голямата честота на дехисценциите на темпоралната кост в различни анатомични проучвания, в литературата не е описано наличието на холестеатом на външния слухов проход и същевременно дефект на тегмена на контралатралната темпорална кост. Ние считаме, че последното представлява повече от просто съвпадение.

Друг въпрос, който бихме желали да дискутираме, е възможната патогенеза на холестеатома в нашия случай. В литературата се подчертава, че посттравматичните холестеатоми на ВСП се развиват вследствие на попадане на епител във фрактурните линии или поради акумулация на кератин зад посттравматична стеноза на канала. ${ }^{4,}{ }^{15}$ Втората възможност според нас не би се различавала от така наречените холестеатоми при конгенитална атрезия или стеноза на ВСП или всяка стеноза независимо от генезата и считаме, че би било поподходящо тези състояния да се обозначават като кератозис обтуранс. От друга страна, по отношение генезата на пьрвичните холестеатоми на ВСП има две теории: 1) нарушена миграция на епитела и 2) исхемия. ${ }^{16,17}$ Първата хипотеза бе отхвьрлена от Бондинг, а втората бе потвърдена от Наим. ${ }^{18,19}$ В нашия случай ние предполагаме следния възможен вариант за появата на заболяването: възможно е травмата на канала да е довела до нарушено кръвоснабдяване на медиалната му част и исхемия, която да провокира изявата на ангиогенните растежни фактори, описани от Наим, и впоследствие усилена кератинизация, която затруднява иначе нормалната миграция на епитела. По този начин бихме обяснили и наличието на кератинов материал върху тъпанчевата мембрана постоперативно и липсата на кератинова тапа 6 месеца по-късно.

\section{Заключение}

Диференциацията между холестеатома на ВСП и кератозис обтуранс в някои случаи може да бъде много трудна. От друга страна, холестеатомът може да има обща генеза с дефектите на тегмена на темпоралната кост. Същевременното наличие на тези състояния в двете противоположни темпорални кости не е описано. Считаме, че причината за дефекта на тегмена е травма, която освен това е стимулирала и патогенезата на холестеатома. 


\section{Литература:}

1. Piepergerdes MC, Kramer BM, Behnke EE: Keratosis obturans and external auditory canal cholesteatoma. Laryngoscope 1980, 90: 383 391

2. Ahren $\mathrm{C}$, Thulin $\mathrm{C}-\mathrm{A}$ Lethal Intracranial complications following inflammation in the external ear canal in treatment of serous otitis media and due to defects in the petrous bone Acta Otolaryngol 1965; 60: 407-421

3. Lundy LB, Graham MD, Kartush JM et al. Temporal bone encephalocele and cerebrospinal fluid leaks Am J Otol 1996; 17: 461-469

4. Brookes GB, Graham MD Post-traumatic cholesteatoma of the external auditory canal Laryngoscope 1984, 94: 667-670

5. Rouev P, Edrev G, Hristova R, Frengov V, Vasilev V Case reposrt of keratosis obturans Transport Medicine 2002; 24: 54-56

6. Persaud RA, Hajioff D, Thevasagayam MS, Wareing MJ, Wright A Keratosis obturans and external ear canal cholesteatoma: how and why we should distinguish between these conditions. Clin Otolaryngol Allied Sci 2004, 29: 577-581.

7. Bharadwaj VK, Walling KE, Rees $\mathrm{J}$ et al. Necrosis and sequestration in the tympanic part of the temporal bone J Otolaryngol 1984; 13: 299 $-304$

8. Naiberg J, Berger G, Hawke M: The pathologic features of keratosis obturans and cholesteatoma of the external auditory canal. Arch Otolaryngol 1984, 110: 690-693.

9. Naim R, Linthicum F Jr., Shen T, Bran G, Hormann K: Classification of the external auditory canal cholesteatoma. Laryngoscope 2005, 115 : $455-460$.
10. Hartley C, Birzgalis AR, Hartley RH, Lyons TJ, Farrington WT External ear canal cholesteatoma, case report Ann Otol Rninol Laryngol 1995; 104: $868-870$

11. Holt JJ Ear canal cholesteatoma Laryngoscope 1992; 102: 608-613

12. Saunders NC, Malhotra R, Biggs N, Fagan PA. Complications of keratosis obturans. J Laryngol Otol. 2006 Sep; 120(9): 740-4

13. Sapci T, Ugur G, Karavus A, Agrali N, Akbulut UG Giant cholesteatoma of the external auditory canal Ann Otol Rninol Laryngol 1997; 106: 471-473

14. Vrabec JT, Chaljub G: External canal cholesteatoma. Otol Neurotol 2002, 23: 241-242.

15. Tos M Cholesteatoma of the external acoustic canal In Manual of middle ear surgery vol 3 Surgery if the external auditory canal Thieme; 1997: 205-209

16. Makino K, Amatsu M: Epithelial migration on the tympanic membrane and external canal. Arch Otorhinolaryngol 1986, 243: 39-42.

17. Farrior J: Cholesteatoma of the external ear canal. Am J Otol 1990, 11: 113-116.

18. Bonding P, Ravn T. Primary cholesteatoma of the external auditory canal: is the epithelial migration defective? Otol Neurotol. 2008 Apr; 29(3): 3 34-8.

19. Naim R, Riedel F, Gotte $\mathrm{K}$ et al. Co-expression of different angiogenic factors in external auditory canal cholesteatoma Acta Otolarygologica 2004; 124:5. 